\title{
The relationship of arrhythmias to walking activity during mobilization after myocardial infarction
}

\author{
J.M. Roland ${ }^{1 *}$, D.C. Banks ${ }^{1}$, B. Edwards ${ }^{2}$ and P.H. Fentem ${ }^{2}$ \\ ${ }^{1}$ Department of Therapeutics, Nottingham City Hospital and ${ }^{2}$ Department of Physiology and Pharmacology, \\ Queen's Medical Centre, Nottingham, UK.
}

\begin{abstract}
Summary: The extent to which everyday walking activity is responsible for ventricular arrhythmias in the first 6 weeks after suspected myocardial infarction has been studied by simultaneous 24-hour recordings of electrocardiogram and walking activity. Forty-eight recordings from 46 patients were identified which contained couplets, ventricular tachycardia or R-on-T extrasystoles. In 24 recordings (50\%) all the arrhythmias occurred whilst the patient was at rest and in a further four recordings there were fewer arrhythmias during activity than would have been expected by chance. Nineteen recordings $(40 \%)$ contained arrhythmias which may have been induced by activity but in only three of these was the relationship definite. Clear evidence of arrhythmias precipitated by walking was found in only a minority of patients mobilizing after suspected myocardial infarction.
\end{abstract}

\section{Introduction}

The occurrence of ventricular arrhythmias in the weeks following a myocardial infarction has attracted much attention, yet comparatively few attempts have been made to define the circumstances in which such arrhythmias occur. Physical activity may be of particular importance and has been incriminated in cases of out-of-hospital ventricular fibrillation (Liberthson et al., 1974; Schaffer \& Cobb, 1975). Although exercise, stress testing and ambulatory monitoring have been extensively compared for their ability to expose arrhythmias (Ryan et al., 1975; Poblete et al., 1978), it is not clear to what extent arrhythmias detected during 24 hour monitoring are induced by physical activity.

We have studied patients mobilizing after suspected myocardial infarction and have used simultaneous 24 hour recordings of electrocardiogram (ECG) and walking activity to separate arrhythmias into those occurring whilst the patient is walking and those occurring at rest.

\section{Methods}

The patients studied had been admitted to a Coronary Care Unit within 24 hours of a suspected myocardial infarction and were free of serious haemodynamic

*Correspondence and present address: J.M. Roland D.M., M.R.C.P., Peterborough District Hospital, Thorpe Road, Peterborough PE3 6DA, UK.

Accepted: 25 September 1985 impairment. They were recruited from a trial of betablockers and received either propranolol $120 \mathrm{mg} /$ day, atenolol $100 \mathrm{mg} /$ day or identical placebo tablets. None were on other anti-arrhythmic therapy. At discharge from hospital the patients were classified according to WHO criteria (WHO, 1976) into those who had had an infarction, the 'Definite' category, and those in whom an infarction was not substantiated, the 'Possible' category. All patients were followed for 12 months or until death.

This report is based on ECG and walking activity recordings made twice; firstly on the medical ward at least 5 days after admission (mean 7 days) when the patients were only partially mobilized and secondly at outpatients 6 weeks after admission when mobilization was complete.Oxford Instruments Medilog tape recorders and standard cassette tapes (Phillips C-120) were used to record the ECG from chest electrodes and walking activity from a simple electrical pedometer worn under one heel (Barber et al., 1973). No restrictions (apart from bathing) were placed on the patients, indeed, they were encouraged to undertake their normal activities.

Arrhythmias were identified using the Oxford Instruments DA-11 ECG analysis system. Advancedgrade arrhythmias were defined as grades 4 and 5 of the Lown and Wolf classification (1971). Couplets were defined as 2 , and ventricular tachycardia (VT) as 3 or more, extrasystoles separated by no more than 500 milli-seconds (heart rate greater than 120 beats/ minute). R-on-T extrasystoles occurred such that the 
RR/QT ratio was less than 0.85 . The results of the arrhythmia analysis have been reported elsewhere (Roland et al., 1979) and the relationship of isolated extrasystole frequency to physical activity has also been studied (Roland, 1980). This study is concerned with further analysis of those recordings which contained advanced-grade arrhythmias in order to determine the relationship of the arrhythmias to activity.

Sections of recording known to contain arrhythmias were replayed at 25 times real time on an Oxford Instruments MAPB replay unit, the ECG and pedometer signals being simultaneously displayed on photographic paper using a Medilec FOR-4 oscilloscope. Figure la shows the record of a patient at rest. The pedometer signal is flat, there are no arrhythmias and the heart rate is 64 beats/minute. Figure $1 \mathrm{~b}$ shows the same patient during a period of activity. The pedometer signal shows a continuous series of oscillations, each representing an individual step of the foot under which the pedometer is placed. There are frequent couplets in the form of trigeminy and the heart rate has increased to 110 beats/minute. The integrity of the pedometer system was checked in each recording by ensuring that known periods of walking at the start and towards the end of the recording appeared as oscillations on the pedometer trace. Although the pedometer trace is subject to electrical artefact this is usually easy to distinguish from true walking which is of a much slower time course.

At least five minutes of record before each arrhythmia were used to classify the arrhythmia into one of three categories according to its relationship with activity. Continuous walking: the arrhythmia was associated with a continuous series of steps each separated from the last by no more than 1.5 seconds or the arrhythmia occurred within 2 minutes of such a period lasting at least one minute. 'Pottering': the arrhythmia occurred within 2 minutes of intermittent steps. Rest: no steps had occurred in the 2 minutes before the arrhythmia.

The time spent on continuous walking was
Table I Numbers of recording with arrhythmia and numbers of episodes of arrhythmia during activity and at rest

\begin{tabular}{|c|c|c|c|c|}
\hline \multirow[b]{2}{*}{ Activity } & \multirow{2}{*}{$\begin{array}{l}\text { No. of } \\
\text { recordings } \\
\text { with an } \\
\text { arrhythmia }\end{array}$} & \multicolumn{3}{|c|}{ No. of episodes } \\
\hline & & $R-o n-T$ & $V T$ & Couplets \\
\hline $\begin{array}{l}\text { Continuous } \\
\text { walking }\end{array}$ & 10 & 1 & 24 & 299 \\
\hline Pottering & 19 & 3 & 14 & 230 \\
\hline $\begin{array}{l}\text { Total } \\
\text { ambulant }\end{array}$ & 24 & 4 & 38 & 529 \\
\hline Rest & 38 & 24 & 45 & 394 \\
\hline
\end{tabular}

measured by computer (Fentem et al., 1976) and total time spent ambulant (walking and pottering) was estimated from a continuous paper write-out of the pedometer signal at a paper speed of $2 \mathrm{~mm} /$ minute.

\section{Statistical analysis}

The frequency of episodes of arrhythmia when ambulant was compared with the frequency at rest and the frequency of arrhythmias associated with continuous walking was compared with the frequency when continuous walking was not occurring. Arrhythmias were assumed to be binomially distributed and statis tical significance was obtained by reference to binomial distribution tables.

Comparisons of the numbers of patients or recordings in different groupings were made by a Chisquared test with Yates' correction for continuity or Fisher's exact test according to numbers.

\section{Results}

Twenty-one of 76 ward recordings and 28 of 92 outpatient recordings contained advanced-grade arr-

\section{a}

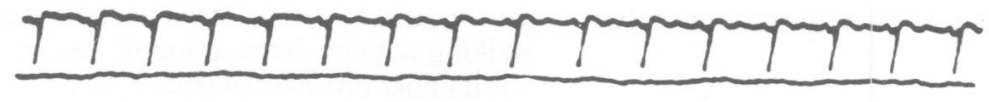

b

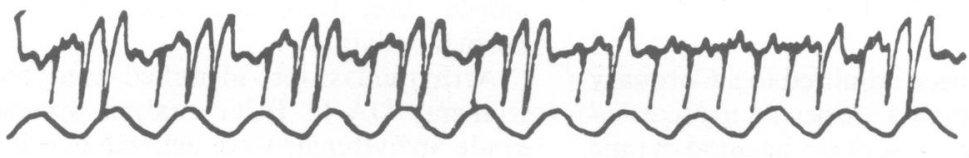

ECG

Pedometer

\section{ECG}

Pedometer

$15 \mathrm{~s}$

Figure 1 ECGs and simultaneous pedometer traces of patient (a) at rest; (b) whilst walking. 
Table II Details of patients whose arrhythmias were associated with activity

\begin{tabular}{|c|c|c|c|c|c|c|c|c|}
\hline \multirow[b]{3}{*}{ Patient } & \multirow{3}{*}{$\begin{array}{c}\text { Total time } \\
\text { spent } \\
\text { walking } \\
\text { (minutes) }\end{array}$} & \multirow{3}{*}{$\begin{array}{l}\text { Total time } \\
\text { ambulant } \\
\text { (minutes) }\end{array}$} & \multicolumn{6}{|c|}{ Number of episodes of arrhythmia } \\
\hline & & & \multicolumn{2}{|c|}{ Walking } & \multicolumn{2}{|c|}{ Pottering } & \multicolumn{2}{|c|}{ Rest } \\
\hline & & & $V T$ & Couplets & $V T$ & Couplets & $V T$ & Couplets \\
\hline $\mathbf{W} . \mathbf{W}$ & 73 & 370 & 5 & 268 & 2 & 184 & 12 & 70 \\
\hline H.B. & 34 & 230 & 18 & 9 & 一 & - & - & - \\
\hline F.M. & 163 & 720 & - & 12 & 2 & 5 & - & 2 \\
\hline
\end{tabular}

hythmias. However, one ward recording was excluded as the pedometer became displaced during the recording. Two patients had significant arrhythmias on both ward and outpatient recordings and all four of these recordings have been included. Therefore 48 recordings from 46 patients form the basis for this study.

The median time ambulant was 1 hour 50 minutes (range 30 minutes to 6 hours 40 minutes) for patients on the ward and 5 hours 40 minutes (range 2 hours 50 minutes to 12 hours) at outpatients. The median time spent in periods of continuous walking was 18 minutes (range 7 to 75 minutes) on the ward and 82 minutes (range 33 to 203 minutes) in outpatients.

The number of recordings with arrhythmias during rest and whilst ambulant and the number of episodes of arrhythmia during these times are given in Table $I$. In all 38 recordings in which arrhythmias occurred at rest the arrhythmias all appeared at least 4 minutes after any footstep. In 24 recordings $(50 \%$ of all recordings) the arrhythmias occurred solely at rest. Twenty-four recordings had one or more episode of arrhythmia occurring during pottering or walking. However, in four of these recordings there was a higher frequency of arrhythmia during rest. Thus 20 recordings had a greater frequency of arrhythmias during activity than at rest. However, in some of these cases the difference was likely to be fortuitous with individual arrhythmias occurring during activity by chance and in only seven cases did the difference in frequency achieve the significance level of $P<0.05$. This conventional level of significance has, however, little meaning as 48 individual comparisons were being made and a level of significance of $P<0.001(0.05$ divided by 48 ) is probably more appropriate. Three recordings achieved this level of significance (Table II). All three were outpatient recordings, two from patients taking atenolol and who had a 'definite' infarction and the other was taking placebo and had had a possible infarction. All arrhythmias associated with continuous walking in these patients appeared at least 25 seconds after starting to walk. The arrhythmias from these three patients accounted for approximately $90 \%$ of all arrhythmias occurring on activity.

Table III shows that there appeared to be little influence of occasion of recording, drug treatment, category of infarction or site of infarction on the proportion of patients with arrhythmias on activity and there were no significant differences between any of the sub-groups.

Four patients died from cardiac causes within 12 months. Three of these had arrhythmias which occurred solely at rest whilst the other had arrhythmias during pottering and rest.

\section{Discussion}

Arrhythmias which occur during 24 hour ECG monitoring may be induced by physical exertion or emotion or may be random events. A pedometer allows a much more precise assessment of activity than is possible from diary cards (Ward et al., 1980) and is free from the restriction of cine photography. The technique is limited by being able to detect walking activity

Table III Numbers of recordings with arrhythmias at rest and during activity according to occasion of recording, drug treatment and category and site of infarction

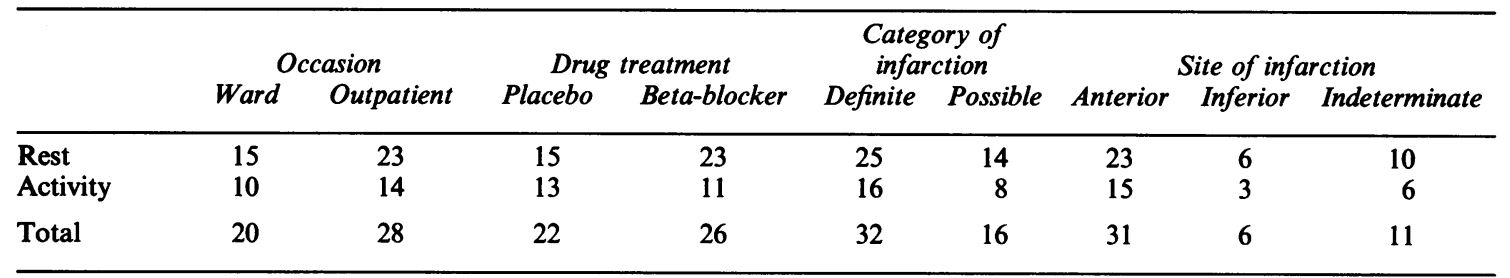


only. All arm work and isometric leg work remains undetected by the pedometer. Arrhythmias which occur at times of activity may not be related to that activity but may have occurred by chance. Furthermore even when arrhythmias can be convincingly related to activity it must be borne in mind that this may not be causative as other factors such as emotional stress may be occurring.

The results of this study may have been influenced by the fact that some of the patients were taking betablockers and in some the diagnosis of infarction was not proven. However, there was little difference in results between the treatment groups or between the categories of infarction. Moreover two of the three patients in whom a definite relationship of arrhythmia frequency to activity could be demonstrated were taking atenolol. Thus it would not seem that the betablockers substantially altered the results of this study.

\section{References}

BARBER, C., EVANS, D.F., FENTEM, P.H. \& WILSON, M.F. (1973). A simple load transducer suitable for long-term recording of activity patterns in human subjects. Journal of Physiology, 231, 94.

FENTEM, P.H., FITTON, D.L. \& HAMPTON, J.R. (1976). Long term recording of activity patterns. Postgraduate Medical Journal, 52 (Supplement 7), 163.

LIBERTHSON, R.R., NAGEL, E.L., HIRSHMAN, J.C., NUSSENFELD, S.R., BLACKBOURNE, B.D. \& DAVIS, J.H. (1974). Pathophysiologic observations in prehospital ventricular fibrillation and sudden cardiac death. Circulation, 49, 790.

LOWN, B.\& WOLF, M.A. (1971). Approaches to sudden death from coronary heart disease. Circulation, 44, 130.

POBLETE, P.F., KENNEDY, H.L. \& CARALIS, D.G. (1978). Detection of ventricular ectopy in patients with coronary heart disease and normal subjects by exercise testing and ambulatory electrocardiography. Chest, 74, 402.

ROLAND, J.M., WILCOX, R.G., BANKS, D.C., EDWARDS, B.,
In $58 \%$ of recordings the arrhythmias either all occurred at rest or occurred at a greater frequency at rest than during activity. Some arrhythmias in the remaining recordings may have been related to activity but this was definitely the case in only three of the 48 recordings. Furthermore, these three recordings accounted for approximately $90 \%$ of all the episodes of arrhythmia occurring during activity. Thus in this study arrhythmias could be related to physical activity in only a minority of cases.

\section{Acknowledgements}

We should like to thank the physicians at the Nottingham City and University Hospitals for allowing us to study their patients and we are grateful to $\operatorname{Dr} B$. Shaw for criticising the manuscript. The study was supported by a research grant from Imperial Chemical Industries Limited.
FENTEM, H. \& HAMPTON, J.R. (1979). Effect of beta blockers on arrhythmias during six weeks after suspected myocardial infarction. British Medical Journal, 2, 518.

ROLAND, J.M. (1980). The relationship of ventricular ectopic beat frequency to heart rate and everyday physical activity British Heart Journal, 43, 100.

RYAN, M., LOWN, B. \& HORN, H. (1975). Comparison of ventricular ectopic activity during 24 hour monitoring an exercise testing in patients with coronary heart disease: New England Journal of Medicine, 292, 224.

SCHAFFER, W.A. \& COBB, L.A. (1975). Recurrent ventricular fibrillation and modes of death in survivors of out-ofhospital ventricular fibrillation. New England Journal of Medicine, 293, 259.

WARD, D.E., CAMM, A.J. \& DARBY, N. (1980). Diagnostic value of 24 hour ambulatory ECG monitoring. Biotelemetry and Patient Monitoring, 7, 57.

WHO Regional Office for Europe (1976). Myocardial Infarction Community Registers, 160. WHO: Copenhagen. 